\title{
Irrigation sector in Bulgaria: impact of post-socialist policy reforms
} Insa Theesfeld

\author{
Department of Agricultural Economics and Social Sciences, Faculty of Agriculture and Horticulture, Humboldt University \\ of Berlin, Philippstr. 13, Building 12, Berlin 10099, Germany. Fax: + 49-30-2093-6339. \\ E-mail: insa.theesfeld@agrar.hu-berlin.de
}

Received 14 March 2006; accepted in revised form 18 September 2006

\begin{abstract}
In Bulgaria's irrigation sector, collective action solutions have been propagated by the Bulgarian Government and the World Bank in recent years. However, the introduction of a World Bank Project, the enforcement of the Bulgarian Water Law in 2000 and the Water User Association Act in 2001 find no common ground where collective action can grow. Given that villagers often hardly know anything about the water user associations that had been established on paper, the local situation is closer to one of open access, with efforts by some powerful individuals to exert some authority.

This paper will show that what formally gives the impression of being a devolution-oriented policy reform by turning over decision power in resource management to local communities is, in fact, a further concentration of power in the irrigation sector. Empirical evidence is provided for pseudo devolution which is due to the actual implementation process of Bulgaria's recent legislation in the irrigation sector, which results in a concentration of property rights with state authorities. Likewise, individual actors who are capable of achieving short-term access to and management rights for the resource system are able to take advantage of the actual ambiguous local assignments of property rights and gain private benefits.
\end{abstract}

Keywords: Bulgaria; Collective action; Irrigation management transfer; Policy reform; Property rights; Pseudo devolution; Transition

\section{Introduction}

The central and eastern European transition countries have experienced a simultaneous change from a centralized planned economy to a market-oriented economy and from a communist-determined political system to a democratic political system. In contemporary Bulgaria and other transitional economies, this had a severe impact on the agricultural sector. Irrigation, until recently a major water user in Bulgaria, has been drastically affected. Uneven distribution of Bulgaria's natural water resources over time and

doi: 10.2166/wp.2007.055

(C) IWA Publishing 2008 
space makes irrigation necessary to reduce production risk and insures that the common-pool resource retains continuous high economic importance. Yet, the irrigation systems were built to serve large production units during socialism and do not meet the needs of the huge number of small-scale landowners that emerged following the land restitution process. Moreover, facilities have largely deteriorated, property rights on the infrastructure are ambiguous and water loss in the system amount to $70 \%$ owing to un-maintained facilities and water stealing.

In analysing the effective implementation of policy aspects, disaggregated bundles of property rights that are assigned to various actors and that are exempted from any oversimplified classification must be considered (Schlager \& Ostrom, 1992: 250-251). Any of these bundles may or may not be well defined and their combination influences the incentives of the actors to govern and manage the resource system (Ostrom, 2003). The ambiguous assignment of property rights in transition countries contributes to the complex system of overlapping and controversial assignments of effective rights.

This paper will show that what formally gives the impression of being a devolution-oriented reform, by handing over decision-making power in resource management to local communities, is in fact a further concentration of power in the irrigation sector ${ }^{1}$. It will provide evidence for pseudo devolution which is due to the actual implementation process of Bulgaria's recent legislation in the irrigation sector and which results in a concentration of property rights with state authorities. Likewise, individual actors who are capable of achieving short-term access to and management rights for the resource system are able to take advantage of the actual ambiguous local assignments of property rights and gain private benefits.

Section 2 describes the methods used to gain empirical material. After Section 3 presents the organizational structure in the post-socialist irrigation sector, the impact of infrastructure transformation is highlighted by concentrating solely on those transition issues that are relevant in explaining the changes in property rights and the current ambiguity of property rights in the irrigation sector. Section 5 presents the devolution focus in post-socialist policy reform by outlining the World Bank project, aspects of the Bulgarian Water Law and the Water User Association Act. Section 6 highlights an empirical example of establishing a pseudo water user organization to show a typical case of individuals gaining private benefits by obtaining access and management rights to the irrigation canal system. Section 7 provides three aspects of legislation breakdown, including an analysis of the present amendments to the Water User Association Act. This section exemplifies the divergence between the formal devolution and privatization attempts and the actual further concentration of power with state authorities. Section 8 concludes by taking distributional aspects and power relations into account when transplanting organizational blueprints, such as that of water user associations in Bulgaria.

\section{Methodology}

The study is based on six months of empirical fieldwork subdivided into three phases spanning two and a half years from 2000 until 2002. In addition to interviews with experts in Sofia and with representatives of the regional administration, two kinds of case studies were conducted: (1) In the first

\footnotetext{
${ }^{1}$ Knox \& Meinzen-Dick (2001: 3) distinguish between devolution and decentralization which are sometimes used interchangeably: Devolution indicates the transfer of responsibility and authority over natural resources from the state to nongovernmental bodies, particularly user groups and decentralization refers to authority and management transfers to lower levels of government.
} 
research phase, 17 village case studies provided an overview of the irrigation situation in the villages and allowed for a rough analysis of the main hypotheses. (2) In the two following research phases, four in-depth village case studies were carried out. Two irrigation command areas were selected. In each area, two villages were chosen with one village located directly behind the water dam (top-ender) and the other further back - at the middle or tail-end of the canal and river system.

With the help of explorative and qualitative methods in the first two research phases, including participant observation and around 200 semi-structured interviews, the author analysed the institutional change in Bulgaria's irrigation sector. Among other aspects, the effective changes to property rights at the local level were investigated. In the third research phase more standardized quantitative methods were conducted to elucidate particular research questions on power and trust relationships in the local communities. For this purpose 80 villagers were interviewed using a standardized questionnaire. Most of the interviewees were approached twice (i.e. in two successive irrigation seasons).

Expert interviews in the autumn of 2005 facilitated analysis of the recent proposals to amend the legislation in the water sector.

\section{Organizational structure in the post-socialist irrigation sector}

Currently, two ministries form the head of Bulgaria's hierarchical organizational structure of the irrigation sector. The Ministry of Environment and Water (MEW) is responsible for Bulgaria's water sector, including the environmental supervision of the country's natural water resources and the coordination of the overall water balance. MEW coordinates water supply and demand for the various sectoral components: power, industry, municipality and agriculture. Water consumption in agriculture comprises crop irrigation, livestock breeding and fish farming. The Irrigation Office, which is affiliated with the Plant Growing Directorate of the Ministry of Agriculture and Forestry (MAF) can be considered the coordination unit implementing the state irrigation policy.

MAF delegates the management of the irrigation sector to the Irrigation System Company (ISC), a state firm. The ISC has been registered under commercial law as a stock-holding company with the state as the sole owner. The ISC has a monopoly on irrigation water supply. Irrigation systems based on market coordination such as trading water rights or quotas do not exist. Irrigation sector management is centralized. Decisions are implemented top-down and, currently, there are no opportunities for the agricultural water users to participate. No other organization besides the ISC plays a major role in the irrigation sector. Non-governmental organizations and producer unions, such as the rice producer union, are not well established enough to engage in the irrigation sector. The Union of Water Users was founded on paper at the national level in 1992 and was used for diverse political purposes, depending on the changing political powers (World Bank Office Sofia, 1999: Annex 1). The Union of Water Users can be considered a political organization and not a union of water users that promotes their shared needs. It does not take part in the management of the irrigation sector.

The ISC is responsible for the management, operation and maintenance of all state-owned irrigation and drainage systems in Bulgaria. The ISC supplies water to different users for irrigation and industrial needs. Twenty-three regional branches operate semi-autonomously but answer to the head office in Sofia, especially for financial control. In 1999 the ISC staff comprised 3,289 employees (World Bank Office Sofia, 1999: Annex 1). 


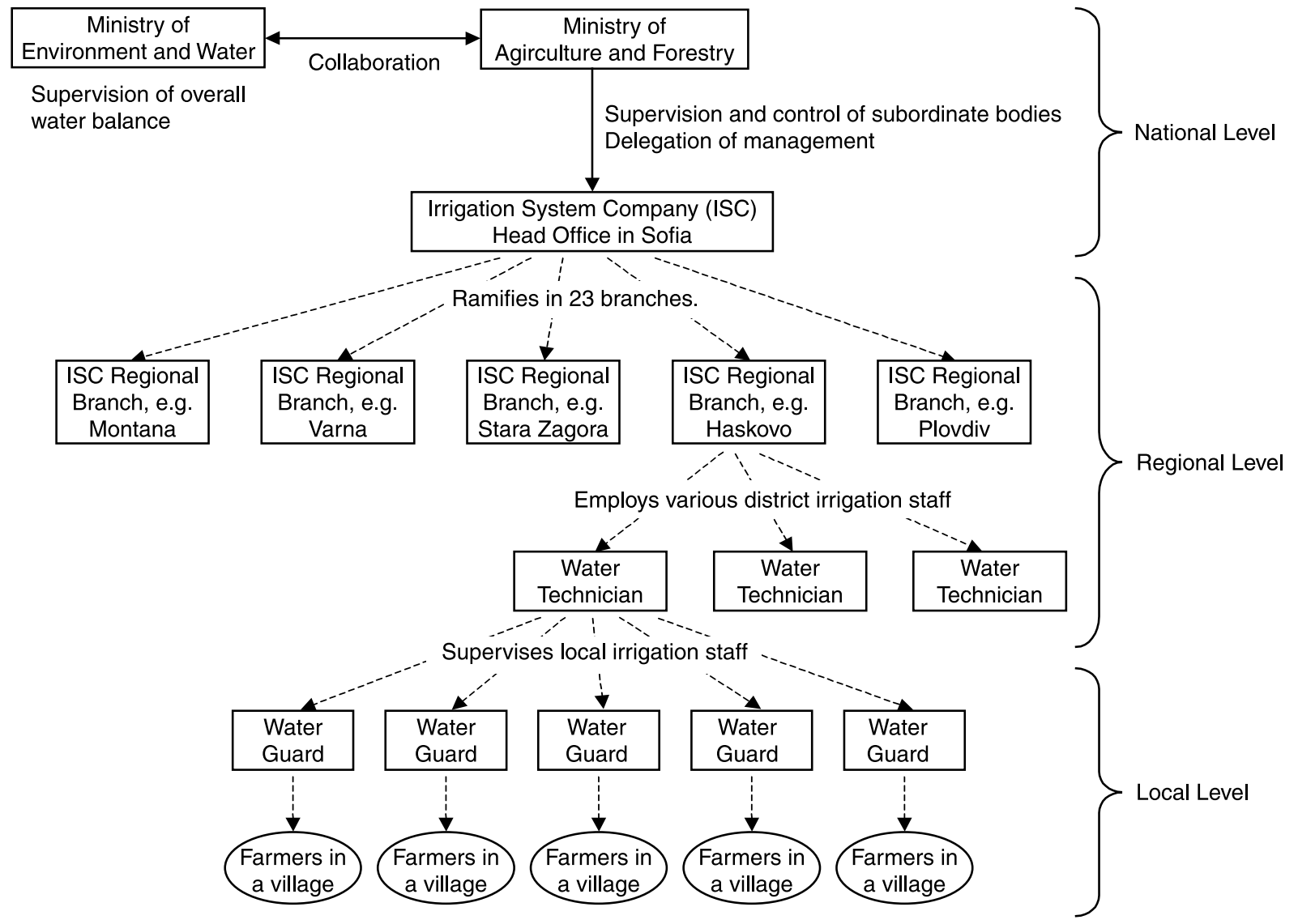

Fig. 1. Organizational structure of Bulgaria's irrigation sector.

Figure 1 illustrates the hierarchical structure of the state-managed irrigation sector in Bulgaria and portrays the leading role of the MEW and the MAF. Figure 1 also depicts the umbrella structure of the ISC from the head office to the 23 regional branches and onto the employees working in the villages. It shows the positions of water technicians and water guards. For reasons of clarity, positions in the ISC that are outside the scope of this paper are not represented in this figure.

Until 1998, there were nine administrative districts including Sofia in Bulgaria. Since January 1999, the country's administrative division has been restructured into six planning regions of 28 districts. The 23 ISC regional branches do not fully comply with these administrative districts in Bulgaria. Nevertheless, the command area of an ISC regional branch is a well-established structure following administrative and technical requirements of an irrigation command area instead of natural hydrological units.

Water technicians are responsible for one or more irrigation command area, depending on size and infrastructure conditions. They coordinate the water supply among different villages, order urgent repairs for the irrigation infrastructure, collect the water fees from water user groups and supervise the water guards, giving them orders and advice. A technician may visit a village once a week to check the local situation. If too many conflicts occur, he or she may visit the village more often to support the water guard in his/her work. 
The water guards are the village representatives of the ISC. From the viewpoint of the water users, especially the small ones, water guards are often the only visible ISC personnel. For the small water users, all matters in the irrigation sector are connected with the water guard. The water guards are usually responsible for coordinating the water supply of one village and are the most important actors in terms of the local water users' daily needs. They organize and rule the local water supply. In addition to the development of irrigation schedules, the water guards operate the internal canal system and collect water fees from smaller water users. Their tasks also include mediating conflicts about the water supply.

The water guards are employed as seasonal workers during the summer months. During the winter they are unemployed and have to wait to negotiate a follow-up contract with the ISC regional branch. In most cases their contracts start shortly before the first irrigation turn. The time remaining does often not allow for maintaining and cleaning the canals. They receive the fixed Bulgarian minimum salary and do not participate in a premium salary system based, for example, on the performance rate of water fee collection. By and large, the water guards come from the village in which they work.

\section{Implication of the irrigation infrastructure transformation}

This section provides information on aspects of the privatization and restitution processes that shaped the transformation of the irrigation infrastructure. During the period spanning 1989 to 1999, Bulgarian governments and the changing holders of political power had hardly developed any concept of how to restructure the irrigation sector and adapt it to the needs of the newly evolving land ownership and production structures. In fact, the transformation of irrigation infrastructure was more a by-product of the land restitution and privatization processes in the agricultural sector (Theesfeld, 2005). Limited strategic decisions regarding irrigation sector reform were made during preparations for the new water sector legislation in 1999 and 2000. With the exception of state-induced reforms, bottom-up processes initiated by water users to transform the irrigation sector rarely evolved. To allow a closer look at the transformation of the irrigation infrastructure, it is roughly divided into three parts:

(a) small-scale infrastructure comprising irrigation equipment and small canals, such as furrows in the fields,

(b) medium-scale infrastructure comprising mid-sized canals, pump stations and micro-dams, and

(c) large-scale infrastructure comprising main distribution canals, large pump stations and water dams.

(a) The Bulgarian privatization was a voucher privatization. Accordingly, parts of the irrigation equipment were redistributed in line with the voucher privatization in the agricultural sector. Within the framework of the liquidation of producer cooperatives, the cooperative farm members received vouchers for the assets of the cooperatives according to their share and their labour input. Individuals could trade the vouchers for assets at a grand auction or exchange different categories of asset vouchers and combine them to bid for larger items (Swinnen \& Mathijs, 1996). Compared to the great demand for basic technical assets, such as tractors, almost nobody was interested in the irrigation equipment. For the cooperative farm members, the demand criterion was what equipment could be used on a small private farm or what could be sold. Of all of the irrigation equipment, only the zinc tubes were considered attractive.

Removable technical assets that were not privatized were subject to "spontaneous privatization" (Rabinowicz \& Swinnen, 1997: 9). In the early 1990s, concrete slabs from the irrigation canals were used for construction works in private houses and estates. Hydrants and underground tubes were dismantled and used for other purposes or sold wherever possible. 
The furrows in the fields were subject to the production decisions of the individual farmer cultivating the corresponding plot. The furrows were retained or destroyed, depending on cropping decisions. Owing to land fragmentation, a plot close to the canal could be planted with cereals, thereby destroying the furrows. Conflicts arise when the farmer of the plot behind this requires irrigation and thus needs the furrows passing through the field of the cereal farmer.

(b) The outcome of the irrigation infrastructure transformation turned out to be most ambiguous for the medium-scale infrastructure (World Bank Office Sofia, 1999: Annex 2). Until now, the ownership rights of certain infrastructure parts have often been ambiguous. There are various agreements in Bulgarian villages concerning the ownership of the medium-scale infrastructure. The internal canal system belongs either to the successor agricultural cooperatives or to the municipalities. In some villages, the vouchers for the internal canal system were turned over to the cooperatives. There was no interest in obtaining these devices, so the cooperatives acquired them. In other villages, the ownership rights to the internal canal system fell to the municipalities. The pump stations were partly assigned to the newly evolving cooperative farms or to the state, depending on the size of the command area they were intended to serve.

In addition to studying the formal ownership structures, the distribution of use rights and maintenance duties should also be examined. The various rights and duties making up the bundles of property rights were not clearly assigned to different entities. For the mid-sized canal system in particular, neither the cooperatives nor the municipalities wanted to take over the duty of operating and maintaining the system. Both parties generally gave the other actor the responsibility for maintenance. As Penov (2002: 12) points out, the municipalities rarely maintained the canal systems. In some places, the ISC state firm took care of sections of the mid-sized canals in order to supply water to big clients. In most places, the water users themselves maintained the canals. The water users comprise mainly small subsistence producers but also cooperatives and a smaller number of commercial farms. More often than not, this maintenance only consisted of cleaning and general repairs to facilitate the water supply for the next season. Water users rarely initiate maintenance with a long-term perspective. Based upon this maintenance conflict, it is easy to understand why mandates are often not clearly set. It remained ambiguous in places where canals were defined as large-scale and medium-scale infrastructure. Actors perceive this ambiguity as a chance to shift inconvenient responsibilities to other parties.

Micro-dams are also considered part of medium-scale irrigation infrastructure and most are in the command of the municipalities, despite the fact that they were built by producer cooperative members during the 1960s. The municipalities frequently lease the dams to fish farmers, who hardly maintain the dams, owing to the lack of incentive for long-term investment in the common one-to-five-year leasing contracts.

A second issue affecting the transformation of medium-scale irrigation infrastructure deals with destruction and theft during transition. During the frequently changing governments that characterized the Bulgarian transition phase, the agricultural cooperatives were put under various temporary managements with changing political and administrative objectives. Liquidation councils in 1991 and 1992 were responsible for the division of cooperatives assets and the destruction or liquidation of the cooperatives (Swinnen, 1997: 130). In 1994 the former communist party-the present Bulgarian Socialist Party (BSP) — won a parliamentary majority. It abolished the liquidation councils and replaced them with "flying troikas", that is three-person committees elected by the members of the cooperatives under liquidation (Swinnen, 1997: 138; Hanisch \& Boevsky, 1999). One objective of the flying troikas was to 
allow the cooperatives undergoing liquidation to register as private cooperatives and to have the assets distributed to them (Swinnen, 1997: 147). The cooperative management turnover, the deliberate chaos and the uncertainty of future ownership of land and farms' assets all paved the way for a period of irrigation infrastructure abandonment, which resulted in poor maintenance, limited guarding of irrigation infrastructure and opportunities for theft and vandalism. The actors were driven in part by economic and in part by political motives.

In 1991 the Union of Democratic Forces (UDF) took over the Bulgarian government as radical reformers and the BSP became the opposition. During that government, which only remained in power until November of 1992, theft and deliberate destruction were supported and partly initiated by the old "nomenklatura", the former communist party officials and related managers in the villages (Swinnen, 1997: 19). Local people confirmed the vandalism as BSP propaganda which seemed to say: "No one else should be able to use what we have built".

Ambiguous property rights and responsibilities with regard to medium-scale infrastructure have lasted until the present.

(c) The ownership rights of a main distribution canals still belong to the state. According to Penov (2002: 6), MAF is responsible for these main canals, while the ISC state firm manages them. Despite these formally well-assigned ownership rights, it is not clear who is responsible for maintaining and cleaning some main canals.

The major water dams supply drinking water and, in some cases, electricity, in addition to irrigation water MEW determines the state policy with regard to management, preservation and planning of the country's water resources, including the sphere of irrigation. It should also determine the priorities of usage of water dams with multipurpose functions (World Bank Office Sofia, 1999: Annex 1). The Ministry of Regional Development is responsible for supplying household drinking water. The Energy Committee controls the electric power stations at the major water dams. Since the MAF is responsible for supplying irrigation water to large-scale infrastructure, these dams are the shared responsibility of three different ministries. This situation has two consequences for the management of major water dams: on the one hand, the facts that water resources are scarce in dry seasons and that the different usages are competing with each other, lead to frequent conflicts that require supply priorities. On the other hand, the different ministries' overlapping responsibilities lead to confusion and management conflict. In general, the redistribution of large-scale infrastructure to the state - and thereby to the ISC state firm-involves economic power and political influence.

\section{Devolution focus in post-socialist policy reform}

In the post-socialist period, a number of Bulgarian laws contained important provisions connected with the changes in property rights regimes of irrigation systems. This section reviews them to the extent necessary to perceive the complicated, modern legal picture of formal rights and duties connected with irrigation. Since 1991, the World Bank has attempted to set up water user organizations (World Bank Office Sofia, 1999). During the same period the Cooperative Law affected the irrigation sector. Thereafter, in light of EU accession, the Bulgarian government enacted two new laws which had major impacts on the irrigation sector: the Bulgarian Water Law, implemented in January 2000 and the Water User Association Act, which came into force in March 2001. Both legal acts claimed to reform and decentralize the formerly centrally planned water sector and increase the involvement of local actors. 


\subsection{World bank project and the cooperative law}

Roughly, the World Bank project can be subdivided into three phases. The pilot phase of the World Bank project lasted from 1991 to 1995 . The objective was to analyse the opportunities for the foundation of water user organizations (WUOs) according to the Turkish model. A small group of experts, mainly employees from the ISC, were trained by the World Bank and conducted field visits to WUOs in Turkey. Finally, four pilot WUOs were established in Bulgaria.

The second phase of the project officially pursued devolution objectives in irrigation management and ran from 1995 until 1996. The World Bank requested the establishment of WUOs as a precondition for granting a World Bank loan to Bulgaria, which was a strong incentive for the government to participate and to support the WUOs' establishment (Koubratova Hristova, 2002). Together with the BSP government, the World Bank hired consultants to organize the setting up of WUOs. In July 1996, one consultant was employed at each ISC regional branch for at least three months. In the World Bank report these consultants were referred to as "local facilitators ... who assisted the start of WUOs" (World Bank Office Sofia, 1999: 4). The consultants did not have to prove their hydromeliorative expertise. It was crucial for the development of the WUOs that the consultants were paid on the basis of the number of registered WUOs, obviously a strong incentive to found as many WUOs on paper as possible. Thus, by the end of 1997, 206 WUOs were reported to have been established, 128 of which were registered at courts (World Bank Office Sofia, 1999: 4).

The third phase of the project began with the termination of the regional facilitator's work by the end of 1996. The World Bank project title "Irrigation Rehabilitation Project" is linked to this third phase. With the help of the project, the World Bank attempted to transfer management responsibilities from the ISC state firm to local WUOs. They should take over the responsibility of operation and maintenance of the irrigation and drainage infrastructure at the local level. The basic idea behind this project was "to manifest the WUOs readiness and willingness to rehabilitate the irrigation facilities managed by them through their own funds" (World Bank Office Sofia, 1999: 6).

Around 1999, the World Bank project was phased out. In 1999, 172 WUOs were reported to have registered with the court. The major share, that is 164 of these organizations, was founded under the Cooperative Law. MAF reported that of the total reported number of WUOs, about 30 were operating actively. Finally, only eight WUOs were listed and received a World Bank credit for rehabilitation of its irrigation facilities. In 1999, the World Bank admitted that only one of the 172 WUOs met all the requirements for an operational WUO, the rest of them existed only on paper (World Bank Office Sofia, 1999: 6). It turned out that the project was frequently used for political purposes varying according to the political parties holding the government power.

Most of the irrigation systems under WUOs command did not represent independent hydrological systems, which means that the ISC sold water to these WUOs. Despite this fact, all WUOs defined the water price for their clients arbitrarily, that is independently of the ISC and the state. This resulted in most cases in artificially high prices, instead of lower prices. The latter is a sign of the strong profit orientation of the initiators. Frequently outsiders not from the villages managed to obtain the use rights to the canal system. By reducing maintenance work to a minimum and not ensuring a reliable water supply, they concentrated on collecting the water fees, partly in advance. Thus, they managed to extract high personal rents, with severe consequences for the already deteriorated infrastructure. There was no financial help from MAF to repair or maintain the infrastructure used by the WUOs, although some founders had hoped additionally to receive state grants or a World Bank loan when establishing a WUO. Most of the WUOs 
either terminated their work voluntarily as the expected financial support fail to appear, or their existence was terminated by MAF after strong protest by the water users who refused to pay the overpriced water fee. In both cases the use rights to the infrastructure fell back to the ISC state firm.

\subsection{The Bulgarian water law}

The Bulgarian Water Law was enforced in January 2000 (State Gazette No. 67/27.07.1999). It specifies the formal ownership structures for the water resources of the country. Property rights, especially control rights, to water usage, and partly to water facility management are designated formally. Property rights specifications - the rights and duties evolving from the ownership and the constraints to ownership — have a larger impact on irrigation practices than the formal ownership structure. For instance, the law restricts private ownership rights to water through, for example, resource quotas limiting the water uptake from wells by landowners to $10 \mathrm{~m}^{3}$ water withdrawal in 24 hours and not more than $0.21 \mathrm{~s}^{-1}$ (Art. 43 (2)). Beyond this limit water users must apply for a permission and pay tax (Art. 44 (1)), yet no control mechanism for the maximum discharges are outlined. This example shows the vagueness of property rights, as long as they are not enforced, which is frequently the case in contemporary Bulgaria.

\subsection{Water user association act and by-laws}

In Bulgaria, a special law for water user associations (WUAs) was enforced in March 2001 (State Gazette No. 34/06.04.2001). The main elements of the Water User Association Act are (a) transferring ownership of internal canal systems from the state to agricultural producers and (b) changing the direction of the decisionmaking process from top-down to bottom-up and thus delegating irrigation system management and property rights to the water users. The introduction to the WUA Act describes the motivation of the law: to adapt the irrigation sector to farm structures and property rights to land that evolved after 1990, as a result of Bulgaria's agricultural reform. The objective of the law is to provide an organizational structure based on democratic principles for the agricultural producers who irrigate their plots.

All WUOs, which had been formally established, had to re-register under the condition of the WUA Act within a period of six months from 1st of April 2001. WUOs which were not re-registered by the end of this period would be terminated and taken off the register. Their irrigation infrastructure would fall back into the management of the ISC state firm.

Article 2 outlines the purpose of the WUAs: "Water User Associations shall be voluntary organizations of natural and legal persons, which, in accordance with the interest of their members and society and through mutual assistance and cooperation, shall perform activities related to the irrigation and drainage of agricultural lands and the maintenance of irrigation and drainage infrastructure on a specified territory".

The operation of WUAs is under the supervision of the state (Art. 5). There are various functions of a supervisory body, which are accomplished by the MAF (Art. 5). For instance, amendments in the WUA's statutes have to be approved by the supervisory body (Art. 16). This supervisory body is specified as a Hydromeliorative Agency in subsequent by-laws. These aspects already show the strong influence of the state within the WUAs-formally community organizations. 


\section{Extracting private short-term rents}

The following section elaborates on the example of founding a WUO and the decisions and actions effected by power abuse that lead to a WUO only existing on paper. In 2000, in one case study village, nonvillagers founded a WUO according to the Cooperative Law. The only precondition was that the founders had to be landowners of plots located alongside the main distribution canal, which serves a number of villages. This foundation was inscrutable for the population of the respective village. For instance, the head of this organization refused to name the other six founders and members. Most of the villagers were unaware of the possibility of establishing a WUO. Likewise, they did not know about the formal existence of a WUO in their village. The villagers spoke of this organization either as a private water firm or as a tenant renting the canal system. The villagers were only aware that the water guard was from their village, without knowing the other parties involved. The water guard was the father of the head of the organization. Since there was at least one connection to a villager, an uncertainty and uneasiness in discussing this topic was evident during the study. Villagers knew hardly anything about the formal existence of the WUO, thus the situation resembled one of open access, with efforts by a formal institution to exert some authority. The effective water ordering and appropriation rules in the village show that the WUO was not an effective company. During the spring of 2001, the water guard employed five pensioners for five days to clean the canals, which was the only maintenance work in the season completed by the WUO.

The manager of the WUO took advantage of the information asymmetry that existed between him and the villagers. He held a leadership position in the Youth Organization of the Peasant Party, which held governmental power in coalition with the UDF from 1997 until 2001. The UDF aimed to increase their political influence in the rural areas by supporting political adherents to found WUOs in rural areas. Owing to his political engagement, the manager of the WUO had access to various kinds of information and could participate in a course offered by the World Bank, in which he was trained to establish WUOs under the Cooperative Law. He used his powerful position, good contacts and supplementary knowledge to establish this WUO. The prestige he had earned by this establishment furthered him in his career in politics. He gained extra income for the collection of water fees and made an additional profit by not spending adequate funds on maintenance work.

It became evident that while ignoring local power structures on the ground, the pure implementation of new formal rules, such as the rules under the Cooperative Law to found a WUO, may again lead to an abuse of power by those individuals who already possess advantageous positions.

\section{Between effective devolution and pseudo process}

The following explores the divergence between the formal devolution and attempts at privatization and the actual concentration of power in the ISC state firm. This can be manifested by analysing the actual WUA registration processes, which shows the competition to be founded between the WUAs and the ISC state firm. As will be revealed, the chosen formal registration procedure hinders rather than favours WUA foundations. Furthermore, the fact that the WUA Act grants of no more than an opportunity for a use rights transfer is discussed. Finally, the implementation of three specifications in the present amendments to the WUA Act are analysed. 


\subsection{Decision power and membership of the temporary committee}

In contrast to the registration of a WUO under the former Cooperative Law, the registration of a WUA under the WUA Act is strictly regulated. To start the procedure to establish a WUA, a local "Constituent Committee" has to be founded, which comprises at least five persons who possess the title deeds of their land and who are served by the same single irrigation system. This group of people has to apply for the "opening of an establishment procedure" (Art. 8(2)). The Hydromeliorative Agency has to decide as a supervisory body on the application and eventually ratify the order for the opening of an establishment procedure (Art. 9). In the following, the implementation of the WUA Act, referring to these two regulations, is demonstrated. A description is given of the stipulated procedure to register a WUA-once the application has reached the national authorities.

In contrast to the legal requirements, up to July 2002 no Hydromeliorative Agency had been established with deciding power over applications to open the procedure to establish a WUA. The latter duty, particularly, has been taken over by a temporary committee. Insiders call this temporary committee a "stop block" indicating that it slows down of the management devolution process on purpose.

A first indication of the actual concentration of power with the state authorities can be shown by the membership of this temporary committee which cannot be regarded as neutral as it only comprises specialists from the ISC and MAF. Its composition represents a crucial aspect in regard to the competition between the ISC state firm and the planned WUAs:

- Vice Minister of Agriculture (Chairman)

- Director of the Structural Adjustment Directorate at MAF

- Director of the Finance Directorate at MAF

- Two specialists, representing the irrigation office at the Plant Growing Directorate at MAF

- Executive Director of ISC Head Office in Sofia

- Head of the Irrigation Department of ISC

- Head of the Investment Department of ISC

- Legal expert of the Legal Department of ISC

- Member of the Union of Water Users-without voting rights

- Minute keeper

There is rivalry for control of the mid-sized infrastructure between the ISC state firm and the WUAs. The ISC state firm wants to keep certain irrigation systems under its control, for example, the profitable ones or those with good established relationships to large individual water users, which ensures additional cash flow from bribes. The ISC tries to keep, in particular, those irrigation territories under its control which incorporate a water dam, a barrage or a main distribution canal. These so-called bottlenecks are easy to control and manageable at low cost. The advantage of a WUA for the manager at the ISC head office arises from the fact that his company has to negotiate only with one contractor for a certain territory, assuming that the water dam or the main distribution canal as supplying infrastructure remains under the control of the ISC.

\footnotetext{
${ }^{2}$ The term indicates a two-stage process. The procedure for applying to open establishment procedure is a preliminary requirement, representing only the first stage of the process.
} 
The ISC wishes to outsource other irrigation territories to the water users, especially those with a very small-scale ramified and destroyed canal network. In general, along a growing number of WUAs the ISC loses its legitimate reason to exist. The fear of losing responsibility and hence jobs, triggers off competition between the ISC and the WUAs. In light of high annual subsidies paid by the state in support of the irrigation sector, the status quo puts the ISC in the position to distribute and decide the full amount of subsidies, whereas decentralizing the management would imply a decentralized subsidy distribution, an effect not welcomed by the ISC employees. In addition to the frequent complaints of WUA initiators that ISC regional branches hinder legal establishment procedures, another indication of strong competition is the fact that up to 2002, only one WUA was registered. Moreover, this WUA did not receive water from the ISC but independently from a river. Regarding the competing situation, the empowerment of the ISC managers to decide about the establishment of WUAs, through their representation on the temporary committee, clearly favours the advocates of centralized irrigation system management.

The constituent committee of a planned WUA addresses its application directly to the Minister of Agriculture. The minister acknowledges the receipt of the application and passes it on to his vice minister with a request for examination. After the vice minister has checked the application, it is handed over to the Head of the Irrigation Department in the ISC head office in Sofia. The Department Head in collaboration with the other temporary committee members, reviews, for instance, whether the listed infrastructure and technical devices in the territory of the planned WUA are correctly specified and would allow for a transfer of use rights, or whether the members of the constituent committee have given correct proof of their land ownership by notarization in accordance with Article 8(2) of the WUA Act. The crucial task of the Head of the Irrigation Department is to check whether an application refers to a "technologically isolated irrigation system" and whether it comprises irrigation infrastructure, which is under state ownership and managed by the ISC.

By July 2002, 150 applications have been received for 110 territories. The temporary committee held eight meetings up to July 2002 to decide applications and gave advice to the minister to approve or to dismiss the applications, resulting in 70 orders for the opening of the establishment procedure signed by the minister.

In several cases two applications referred to an identical territory or one identical constituent committee applied for different territories. In cases where more than one application to open an establishment procedure is handed in for an identical territory, the ministry can decide how to proceed. In the latter case, it takes over the role of the constituent committee with the aim either of postponing the decision about the management of the WUA by the water users or of deciding and adjusting the boundaries of the territory directly. There are cases where constituent committees tried to exclude an area from the planned WUA territory, which obviously belonged to the "technological isolated irrigation system". In these cases, the ministry also represents the authority that can decide over territory boundaries. According to the ISC in Sofia, cases where the constituent committees tries to keep the territory small can be explained as follows: first it is easier to find the number of landowners demanded and second it is a convenient way to exclude water users from a WUA, as there is no obligation to supply water outside the territory of the WUA.

After a constituent committee has received an order to open the procedure, the second stage in the application procedure is reached and, in compliance with the WUA Act, further formal steps have to be followed. The initiators have to organize at least two preliminary "constituent meetings", which have to be announced in local and national newspapers. The constituent meeting is legitimate if the persons described in Article 6(2) participate (Art. 11). The objective of the meeting is to compile a list of all potential founders of a WUA. The latter refers to the rule that $51 \%$ of landowners and users who own and use more than $50 \%$ of the agricultural land on the territory have to be founding members. This requirement is restrained by Article 12, 
which states that each founding member may authorize in writing another person to represent him/her at the constituent meeting by his/her signature and by witness of a public notary. In particular, this article involves opportunities to bypass the law. The list of participants in the constituent meeting, as well as the statutes of the planned WUA, have again to be approved by the Minister for Agriculture in subsequent steps.

\subsection{Voluntary use rights transfer}

Another interesting aspect of the WUA Act to be highlighted here concerns the use rights of the infrastructure granted to WUAs and the ownership transfer. Article 47(1) states that: "The associations shall be entitled to acquire use rights, free of charge, over the irrigation facilities as well as the service equipment on the territory of the association, included in the property of trade associations in which the state is a sole trader [i.e. the ISC]. The terms and conditions for transferring and withdrawing use rights shall be in conformity with an ordinance issued by the Council of Ministers on a proposal from MAF". A WUA which uses facilities in compliance with the previous statements "shall be entitled, within a period of up to five years from use right acquisition, to acquire property rights on them free of charge by a decision of the Council of Ministers on a proposal from the MAF" (Art. 47(4)).

At this point a digression to look at the Water Law should help to illustrate the deliberate fuzziness of the laws which enable the state at any time to exert an influence on the irrigation sector. For instance, the text of Article 91(1) of the Water Law declares: "Owners of water economy systems shall be able to concede rights to use over the systems or technologically detached parts of them to a water user association in connection with the subject of activity of the association for a term no longer than ten years". The latter regulations, together with the provisions specified in the WUA Act, specify only an opportunity for establishment of use rights. The granting of use rights to WUAs is not a mandatory obligation but a legal option for the state firm (World Bank Office Sofia, 1999: Annex 4 - Legal Aspects). The World Bank concedes that the granting only of an option to establish a use right is an inadequate legal solution referring to the present crisis in the irrigation sector which additionally hampers investments of the associations. The World Bank concludes that with the Water Law, the rights of the ISC are "partially retained in full", because the ISC remains owner of infrastructure used by the WUOs. For the infrastructure that is declared public state property, a use right for the state firm will be established (World Bank Office Sofia, 1999: Annex 4 - Legal Aspects).

\subsection{Amendments to the water user association act}

There are currently two proposals to amend the Water User Association Act in circulation in Bulgaria-one submitted by the Council of Ministers in March 2004 and the other submitted by a member of the Turkish Party in July 2004. There were a number of first and second readings of these amending bills in plenary sessions in the National Assembly. Nevertheless, these amendments have not been adopted by the parliament. The start of Bulgaria's pre-election period and the parliamentary elections in the summer of 2005 apparently deferred any discussions on the WUA issue.

Three aspects of the first amendment are of particular interest with regard to the devolution processes and the distribution of property rights in the irrigation sector. First, the rights and decision power of the 
Minister of Agriculture is foreseen to be expanded by the proposal ( $\$ 15$ Art. 66(2)). For instance, the minister should approve the statutes of the WUAs and any changes to them. He or she can also start his or her own initiative to found a WUA and can issue an order for the rules concerning the infrastructure use. This opposes the decentralization objective and the claimed aim of devolving responsibilities from the state to the communities; in fact, a concentration of power would result.

Second, WUAs are explicitly required to have an enlarged spectrum of activities, including fish farming in particular ( $\$ 1$ Art. 2). The property right to raise fish in a micro-dam, a very profitable business, is a highly controversial issue. It encourages incentives for self-interested actors to engage in the establishment of a pseudo WUA. Fish farmers and crop farmers are often in conflict with each other: During the summer, or fish-growing season, the water level is either kept high for fish farming, or water is released for irrigation purposes. During autumn, the water level in the dam is either reduced to fish out, or the water is stored until the following spring irrigation season. The fish farming business is a part of Mafia-like structures in Bulgaria. Thus, the micro-dams are heavily guarded and neither water users nor the local authorities are willing to begin negotiations on the release of water for irrigation purposes. Some village municipalities regularly receive the micro-dam rental fee as well as additional payments that help tolerate the conflict. Granting this particular right - the right to farm fish — to the WUAs carries the risk of shifting the motivation WUA founders away from the original aim of collective and self-organized management of the irrigation infrastructure and towards a misuse of the WUA concept, for individual profit. Capable self-interested actors may try to obtain the use rights for the micro-dam to maximize their profit.

Third, the number of persons necessary to found a WUA should be reduced. This refers to Article 6(2) and the $51 \%$ rules. At first glance, this change in procedural rules leads to simplified practices and a reduction in obligation but bears the risk of misuse by making it easier for village outsiders with incentives other than organizing collective action to initiate a pseudo WUA. It would reduce the burden of collecting a large number of signatures, a formal requirement that already has been relatively easy to bypass.

The last two aspects show that the analysis of disaggregated property rights and obligation is necessary, as tiny changes in particular property rights might be responsible for (1) a change in incentive to manage the resource and (2) the effectiveness of the formal objectives of the law that call for collective action and self-governance in the irrigation sector.

In general, no measures in the amendments to the WUA Act could be found that would directly facilitate the emergence of collective action - such as spreading information, strengthening the advisory system, or increasing interpersonal trust among the rural community members. The last is regarded as a basic prerequisite for the emergence of collective action.

\section{Conclusion}

The post-socialist policy reforms in Bulgaria's irrigation sector point to a formal institutional arrangement of a common-property regime, including property rights regarding the large-scale infrastructure assigned to the ISC state firm, but the effective local rule seems to be open access-which is not a property regime. The paper has shown that instead of the irrigation sector's formally claimed devolution process - transfer of responsibilities and authorities from state to local communities-there is a further concentration of decision power with the state authorities by means of legislation breakdown. These tiny but significant changes in property rights can only be observed by disaggregating the diversified assignments of effective bundles of property rights. 
The paper indicates that —owing to the particularities of the transition process - there are ambiguous property rights assignments regarding the irrigation infrastructure, particularly at the local level. There is manifold empirical evidence that these unclear assignments allow individuals to engage in the irrigation sector and extract private short-term rents. As a result, the infrastructure further deteriorates.

It can be concluded that the transplantation of organizational blueprints, such as those of water user associations, will not be effective in Bulgaria unless distributional aspects and power relations are taken into account. Actors who fear losing their powerful favourable positions will oppose the new formally implemented rules. Likewise, self-interested actors manage to misuse the rules for private short-term benefits instead of engaging in the objectives of water user associations, that is, the setting up of selfgoverned community organizations to ensure long-term sustainable resource management. The misuse intensifies the existent low level of trust among citizens and in such kinds of community organizations. Thus, it contributes to the persistent deterioration of social capital, which is otherwise a prerequisite for collective action.

\section{References}

Amending Bill to the Water User Association Act (2004). Amending Bill submitted by Council of Ministers on 04.03.2004 and by Dzhevdet Chakarov on 19.07.2004.

Hanisch, M. \& Boevsky, I. (1999). Political, institutional and structural developments accompanying land reform and privatization in Bulgarian agriculture. Südosteuropa, Zeitschrift für Gegenwarts-Forschung, 48(7-8), 446-464.

Knox, A. \& Meinzen-Dick, R. (2001). Workshop summary. In Collective Action, Property Rights and Devolution of Natural Resource Management: Exchange of Knowledge and Implications for Policy. Meinzen-Dick, R., Knox, A. \& Di Gregorio, M. (eds). Feldafing, Germany: Zentralstelle für Ernährung und Landwirtschaft, pp. 1-33.

Koubratova Hristova, M. (2002). Bulgarian water user associations: situation and problems. Paper presented at the Central and Eastern European Sustainable Agriculture (CEESA) - Bulgarian Policy Learning Workshop, July 18-21, Plovdiv, Bulgaria.

Ostrom, E. (2003). How types of goods and property rights jointly affect collective action. Journal of Theoretical Politics, 15(3), 239-270.

Penov, I. (2002). The Use of Irrigation Water during Transition in Bulgaria's Plovdiv Region. CEESA Discussion Paper No. 7. Humboldt University of Berlin.

Rabinowicz, E. \& Swinnen, J. (1997). Political economy of privatization and decollectivization of central and east European agriculture: definitions, issues and methodology. In Political Economy of Agrarian Reform in Central and Eastern Europe. Swinnen, J. (ed.). Ashgate, Aldershot, pp. 129-158.

Schlager, E. \& Ostrom, E. (1992). Property-rights regimes and natural resources: a conceptual analysis. Land Economics, 68(3), $249-262$.

Swinnen, J. (1997). On liquidation councils, flying troikas and Orsov co-operatives: the political economy of agricultural reform in Bulgaria. In Political Economy of Agrarian Reform in Central and Eastern Europe. Swinnen, J. (ed.). Ashgate, Aldershot, pp. 129-158.

Swinnen, J. \& Mathijs, E. (1996). Agricultural privatization, land reform and farm restructuring in central and eastern Europe: a comparative analysis. Paper presented at the COST-Conference on "Agricultural Privatization, Land Reform and Farm Restructuring in Central and Eastern Europe. June 14-16, Sinaia, Romania.

Theesfeld, I. (2005). A common-pool resource in transition. Determinants of institutional change in Bulgaria's postsocialist irrigation sector. Institutional Change in Agriculture and Natural Resources. Volume 23. Shaker, Aachen.

World Bank Office Sofia (1999). Irrigation Rehabilitation Project. Main Report. World Bank Office, Sofia. 